\title{
A Bootstrap Approach of Benchmarking Organizational Maturity Model of Software Product With Educational Maturity Model
}

\author{
Prof. R.Manjula \\ School of Computing Sciences and Engineering, Vellore Institute of Technology, India \\ Email:rmanjula@ vit.ac.in \\ Prof. J.Vaideeswaran \\ School of Computing Sciences and Engineering, Vellore Institute of Technology, India \\ Email: jvaideeswaran@ vit.ac.in
}

\begin{abstract}
This Software product line engineering is an inter-disciplinary concept. It spans the dimensions of business, architecture, process, and the organization. Similarly, Education System engineering is also an interdisciplinary concept, which spans the dimensions of academic, infrastructure, facilities, administration etc. Some of the potential benefits of this approach include continuous improvements in System quality and adhering to global standards. The increasing competency in IT and Educational Sectors necessitates a process maturity evaluation methodology. Accordingly, this paper presents an organizational maturity model for Education system for evaluating the maturity of multi- dimension factors and attributes of an Education System. Assessment questionnaires and a rating methodology comprise the framework of this Educational maturity model. The objective and design of the questionnaires are to collect information about the Education system engineering process from the multi perspectives of academic, infrastructure, administration, facilities etc. Furthermore, we conducted one case study and reported the assessment results using the organizational maturity model presented in this paper.
\end{abstract}

Index Terms - SEI-CMM, BOOTSTRAP, Software quality, Process improvement, Process maturity

\section{BACKGROUND}

There is a lot of similarity between the software situation that prevailed in the world a few years ago and the IT/engineering education situation currently prevailing in the country [1]. To take control of this situation, the department of defense in the US, which was the major customer for software, set up the software engineering institute (SEI). The charter of SEI was to evolve the capability maturity model (CMM) which can be used to provide suitable visibility into the capability of a supplier for providing the software service.

The current situation in technical and management education in India is similar. Due to the high demand, fueled largely by the boom in knowledge-based industries like the IT sector, many private colleges have come up for education in IT, engineering, and management currently $90 \%$ or more of the colleges are private. Many of these colleges and institutes do not have the capability of providing the training they claim to provide, but the customer (the students and parents) have no way to judge their capability, and "buy" the education at high prices

\section{INTRODUCTION}

Clearly, the CMM for education will look very different in details than CMM for software [1]. However, there are some general properties of such a framework. First, the overall capability of a service provider can be represented by a few levels. It is now recognized that a two-level accreditation systems, like the ISO-certified or ISI-mark are suitable for some sectors like the manufacturing sector, but are not well suited for service sector. For a service sector, it is much better to have a framework that is multi-level, such that capability of delivering quality has a finer gradation. Then for each level, a few key aspects of providing the service (called the Key Process Areas or KPAs in the CMM for software) [5] at a certain level are specified. During an assessment, each of these areas are evaluated and rated with weaknesses and strengths identified. And if all the areas of a level are fully satisfied, then the organization is supposed to be at that level. For a higher level, all areas of that level and the levels below must be satisfied.

For the education sector in India, levels can be defined like in the SPICE model (which is the ISO answer to CMM) which has levels 0 to level 5. Key areas for each level can be defined.

\section{The EducAtion - BoOtstrap Process Model}

This section describes the BOOTSTRAP process taxonomy and framework. The terms and process structure of BOOTSTRAP [2] are introduced using the original form of expression and are contrasted with the unified education process system framework. 


\section{A. Taxonomy of the Education-BOOTSTRAP process model}

The BOOTSTRAP process hierarchy and domains are listed in Table I.

TABLE I. EDUCATIONAL SYSTEM - BOOTSTRAP CONFIGURATION MODEL

\begin{tabular}{|l|l|l|l|l|}
\hline Taxonomy & $\begin{array}{l}\text { Sub- } \\
\text { system }\end{array}$ & Category & Process & Practice \\
\hline Process scope & $\begin{array}{l}\text { Process } \\
\text { areas } \\
\text { (PAs) }\end{array}$ & $\begin{array}{l}\text { Process } \\
\text { Categories } \\
\text { (PCs) }\end{array}$ & $\begin{array}{l}\text { Processes } \\
\text { (PRs) }\end{array}$ & $\begin{array}{l}\text { Quality } \\
\text { system } \\
\text { attributes } \\
\text { (QSAs) }\end{array}$ \\
\hline $\begin{array}{l}\text { Size of } \\
\text { domain }\end{array}$ & 5 & 9 & 45 & 234 \\
\hline Identification & PA[i] & PC[i,k] & PR[i,k,r] & QSA [i,k,r,j] \\
\hline
\end{tabular}

Table I defines the configuration of the BOOTSTRAP model. As shown, the QSAs, PRs, PCs and PAs used in BOOTSTRAP are equivalent to the education practices, processes, category, and levels respectively, as defined in the unified process system framework.

In order to provide a formal identification for each entity defined at various levels of coverage known as process scopes, the indexing of PA, PC, PR and QSA are described using a naming convention as shown in Table I.
In this table, $\mathrm{i}$ is the number of PA; $\mathrm{k}$ - the number of PC in $i^{\text {th }} \mathrm{PA}$; and $\mathrm{j}$ - the number of QSA in $\mathrm{r}^{\text {th }} \mathrm{PR}, \mathrm{k}^{\text {th }} \mathrm{PC}$, and the $i^{\text {th }} \mathrm{PA}$.

\section{B. Framework of the Education - BOOTSTRAP process model}

The fundamental concept of BOOTSTRAP is a set of 234 QSAs. Based on this premise, BOOTSTRAP claims it is an attribute-based method for process assessment and improvement [Kuvaja et al., 1994a]. The QSAs of BOOTSTRAP are classified in two ways: functional and measurable technology [BOOTSTRAP Institute, 1994, Koh 2004].

According to the functional classification, the QSAs are categorized into four process areas known as repeated, defined, refined, and quantifiable managed. According to the measurable classification, for process assessment, BOOTSTRAP specifies the QSAs at different capability levels similar to those of CMM for Software.

From the functional organization point of view, BOOTSTRAP models educational computing based process system into 5 process areas (PAs), 9 process categories (PCs), and 234 processes (PRs) as shown in Table II below.

TABLE II. EDUCATIONAL SYSTEM - BOOTSTRAP CONFIGURATION MODEL

\begin{tabular}{|c|c|c|c|c|c|}
\hline ID & $\begin{array}{l}\text { PA } \\
\text { (Proces } \\
\text { s Area) }\end{array}$ & $\begin{array}{l}\text { PC } \\
\text { (Process } \\
\text { Category) }\end{array}$ & $\begin{array}{l}\text { PR } \\
\text { (Process } \\
\text { Rating) }\end{array}$ & Description & No of QSAs \\
\hline $\mathbf{0}$ & $\mathbf{P A}_{0}$ & & & Initial & 0 \\
\hline 0.1 & & $\mathrm{PC}_{0.1}$ & & Adhoc process & 0 \\
\hline & & & $\mathrm{PR}_{0.1 .1}$ & Adhoc & 0 \\
\hline 1 & $\mathbf{P A}_{1}$ & & & Repeated & 106 \\
\hline 1.1 & & $\mathrm{PC}_{1.1}$ & & Physical Resource Mgt & 14 \\
\hline 1.1 .1 & & & $\mathrm{PR}_{1.1 .1}$ & $\begin{array}{l}\text { Resource } \\
\text { Allocation }\end{array}$ & 6 \\
\hline 1.1 .2 & & & $\mathrm{PR}_{1.1 .2}$ & Financial and resource, allocation & 2 \\
\hline 1.1 .3 & & & $\mathrm{PR}_{1.1 .3}$ & Physical facilities & 6 \\
\hline 1.2 & & $\mathrm{PC}_{1.2}$ & & Academic Resource Mgt & 19 \\
\hline 1.2 .1 & & & $\mathrm{PR}_{1.2 .1}$ & Learning Resources & 7 \\
\hline 1.2 .2 & & & $\mathrm{PR}_{1.2 .2}$ & Course Curriculum & 6 \\
\hline 1.2 .3 & & & $\mathrm{PR}_{1.2 .3}$ & Administrative Support & 6 \\
\hline 1.3 & & $\mathrm{PC}_{1.3}$ & & Human Resource Mgt & 73 \\
\hline 1.3 .1 & & & $\mathrm{PR}_{1.3 .1}$ & Leadership & 7 \\
\hline 1.3 .2 & & & $\mathrm{PR}_{1.3 .2}$ & Staff and Students relationship & 6 \\
\hline 1.3 .3 & & & $\mathrm{PR}_{1.3 .3}$ & Management and organization skills & 7 \\
\hline 1.3 .4 & & & $\mathrm{PR}_{1.3 .4}$ & Communication and social skills & 4 \\
\hline 1.3 .5 & & & $\mathrm{PR}_{1.3 .5}$ & Teamwork & 2 \\
\hline 1.3 .6 & & & $\mathrm{PR}_{1.3 .6}$ & Human Resources(faculty and staff) & 7 \\
\hline 1.3 .7 & & & $\mathrm{PR}_{1.3 .7}$ & Human Resources(students) & 4 \\
\hline 1.3 .8 & & & $\mathrm{PR}_{1.3 .8}$ & Management Responsibility & 10 \\
\hline 1.3 .9 & & & $\mathrm{PR}_{1.3 .9}$ & Product realization. & 5 \\
\hline 1.3 .10 & & & $\mathrm{PR}_{1.3 .10}$ & Measurement, analysis and improvement & 4 \\
\hline 1.3 .11 & & & $\mathrm{PR}_{1.3 .11}$ & Educational Change Management & 8 \\
\hline 1.3 .12 & & & $\mathrm{PR}_{1.3 .12}$ & Teaching-Learning and assessment practices & 9 \\
\hline 2 & $\mathbf{P A _ { 2 }}$ & & & Defined & 54 \\
\hline
\end{tabular}




\begin{tabular}{|c|c|c|c|c|c|}
\hline 2.1 & & $\mathrm{PC}_{2.1}$ & & Up-gradation & 31 \\
\hline 2.1 .1 & & & $\mathrm{PR}_{2.1 .1}$ & Educational subcontract management & 1 \\
\hline 2.1 .2 & & & $\mathrm{PR}_{2.1 .2}$ & Educational organization process focus & 6 \\
\hline 2.1 .3 & & & $\mathrm{PR}_{2.1 .3}$ & Student support and progression & 4 \\
\hline 2.1 .4 & & & $\mathrm{PR}_{2.1 .4}$ & Supplementary practices & 6 \\
\hline 2.1 .5 & & & $\mathrm{PR}_{2.1 .5}$ & Healthy practices & 6 \\
\hline 2.1 .6 & & & $\mathrm{PR}_{2.1 .6}$ & Strategy planning & 2 \\
\hline 2.1 .7 & & & $\mathrm{PR}_{2.1 .7}$ & Opportunities for knowledge up-gradation & 6 \\
\hline 2.2 & & $\mathrm{PC}_{2.2}$ & & Educational Outcomes & 23 \\
\hline 2.2 .1 & & & $\mathrm{PR}_{2.2 .1}$ & Learning outcomes & 6 \\
\hline 2.2 .2 & & & $\mathrm{PR}_{2.2 .2}$ & Technical Competencies & 5 \\
\hline 2.2 .3 & & & $\mathrm{PR}_{2.2 .3}$ & Technology driven teaching aids & 3 \\
\hline 2.2 .4 & & & $\mathrm{PR}_{2.2 .4}$ & Generic Competencies & 9 \\
\hline 3 & $\mathbf{P A}_{3}$ & & & Refined & 46 \\
\hline 3.1 & & $\mathrm{PC}_{3.1}$ & & Continual Improvement & 19 \\
\hline 3.1 .1 & & & $\mathrm{PR}_{3.1 .1}$ & Teaching - Learning and Evaluation & 7 \\
\hline 3.1 .2 & & & $\mathrm{PR}_{3.1 .2}$ & Research, Consultancy and Extension & 8 \\
\hline 3.1 .3 & & & $\mathrm{PR}_{3.1 .3}$ & $\begin{array}{l}\text { Redefining educational quality in terms of } \\
\text { outcomes }\end{array}$ & 4 \\
\hline 3.2 & & $\mathrm{PC}_{3.2}$ & & Global Quality Management & 27 \\
\hline 3.2 .1 & & & $\mathrm{PR}_{3.2 .1}$ & Internal Quality Assurance Cell (IQAC) & 6 \\
\hline 3.2 .2 & & & $\mathrm{PR}_{3.2 .2}$ & Process management & 3 \\
\hline 3.2 .3 & & & $\mathrm{PR}_{3.2 .3}$ & Personality development & 5 \\
\hline 3.2.4 & & & $\mathrm{PR}_{3.2 .4}$ & Academics & 5 \\
\hline 3.2 .5 & & & $\mathrm{PR}_{3.2 .5}$ & Industry Institute Interface & 3 \\
\hline 3.2 .6 & & & $\mathrm{PR}_{3.2 .6}$ & Responsiveness & 5 \\
\hline 4 & $\mathbf{P A}_{4}$ & & & Quantifiable matured process & 28 \\
\hline 4.1 & & $\mathrm{PC}_{4.1}$ & & $\begin{array}{l}\text { Qualifiedly and Quantifiable process } \\
\text { management }\end{array}$ & 28 \\
\hline 4.1 .1 & & & $\mathrm{PR}_{4.1 .1}$ & Organizational performance results & 6 \\
\hline 4.1 .2 & & & $\mathrm{PR}_{4.1 .2}$ & $\begin{array}{l}\text { Quantitative and qualitative focus on teaching } \\
\text { and learning }\end{array}$ & 3 \\
\hline 4.1 .3 & & & $\mathrm{PR}_{4.1 .3}$ & Measurement Analysis and knowledge mgt. & 2 \\
\hline 4.1 .4 & & & $\mathrm{PR}_{4.1 .4}$ & Maturity and stability of the institution & 5 \\
\hline 4.1 .5 & & & $\mathrm{PR}_{4.1 .5}$ & Educational Quality Assurance & 8 \\
\hline 4.1.6 & & & $\mathrm{PR}_{4.1 .6}$ & Continuous Evaluation System & 4 \\
\hline
\end{tabular}

\section{Formal DESCRIPTION OF THE EDUCATION - BOOTSRAP PROCESS MODEL}

The formal description of the Education BOOTSTRAP process model provides precise and accurate definitions of the structure and interrelationships of the BOOTSTRAP processes, and avoids ambiguity inherent in conventional natural language description.

1) CMM Bootstrap Structure

A formal description of the structure of the BOOTSTRAP process model, Educational System BOOTSTRAP, ES-PM, is shown in Expression 1 and illustrated in Fig.2. Basically, this is a process model at the system level.
BOOTSTRAP - PM

$=\mathrm{PA}_{0}\left\|\mathrm{PA}_{1}\right\| \mathrm{PA}_{2}\left\|\mathrm{PA}_{3}\right\| \mathrm{PA}_{4}$

= Initial $\|$ Repeated $\|$ Defined $\|$ Refined $\|$ Quantifiable matured process

Let $\mathrm{PA}_{\mathrm{x}}$ be the process area at xth level $\mathrm{PC}_{\mathrm{x} . \mathrm{y}}$ be the process category $\mathrm{y}$ at $\mathrm{xth}$ level.

$\mathrm{PR}_{\mathrm{x} . \mathrm{y} . \mathrm{z}}$ be the processes $\mathrm{z}$ of $\mathrm{yth}$ process category at $\mathrm{xth}$ category at $x$ th process area

In the BOOTSTRAP process model, each process area can be extended to a number of parallel PCs as shown by a set of expressions in Step 2. 


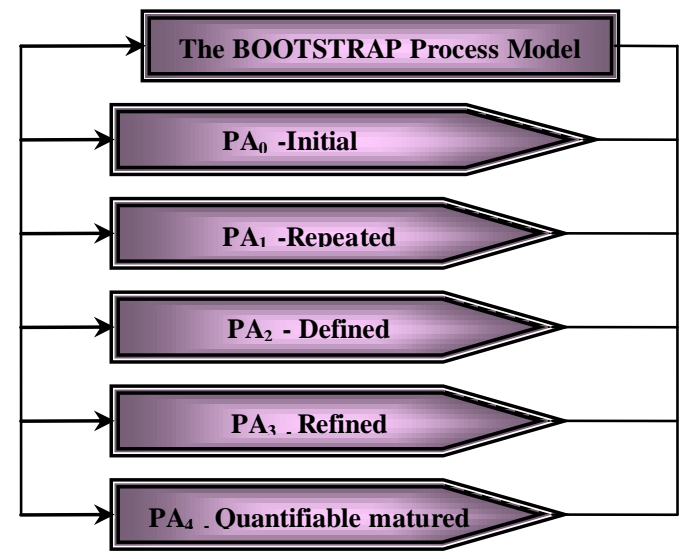

Figure 2: The Educational System - BOOTSTRAP Process model

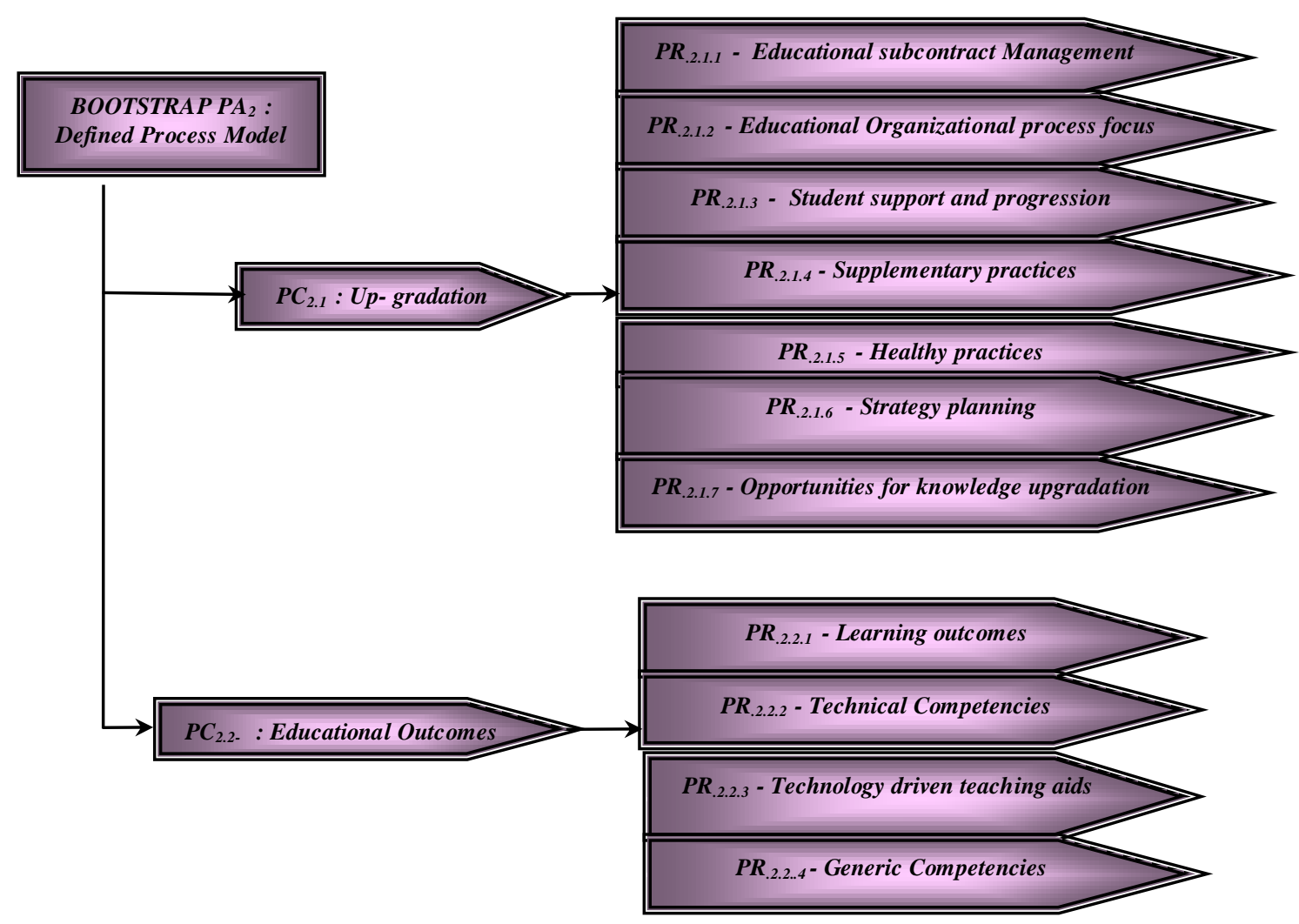

Figure 3: BOOTSTRAP Process Area, $\mathrm{PA}_{2}$ - the methodology processes

The BOOTSTRAP processes known as PRs, at each capability level can be formally defined by a set of expressions as shown in step 3 and are illustrated in Figure 3 for PA2.

STEP-1: Bootstrap process rating,

$\mathrm{PR}=\mathrm{PA}_{0}\left\|\mathrm{PA}_{1}\right\| \mathrm{PA}_{2}\left\|\mathrm{PA}_{3}\right\| \mathrm{PA}_{4}$

STEP-2: Each PA can be extended to a number of parallel PC's

$$
\begin{aligned}
& \mathrm{PA}_{1}=\mathrm{PC}_{1.1}\left\|\mathrm{PC}_{1.2}\right\| \mathrm{PC}_{1.3} \\
& \mathrm{PA}_{2}=\mathrm{PC}_{2.1} \| \mathrm{PC}_{2.2} \\
& \mathrm{PA}_{3}=\mathrm{PC}_{3.1} \| \mathrm{PC}_{3.2} \\
& \mathrm{PA}_{4}=\mathrm{PC}_{4.1}
\end{aligned}
$$

STEP-3: Processes known as PRs at each capability level can be formally defined as 


$$
\begin{aligned}
\mathrm{PA}_{1}= & \mathrm{PC}_{1.1}\left\|\mathrm{PC}_{1.2}\right\| \mathrm{PC}_{1.3 .3} \\
= & \left(\mathrm{PR}_{1.1 .1}\left\|\mathrm{PR}_{1.1 .2}\right\| \mathrm{PR}_{1.1 .3}\right) \| \\
& \left(\mathrm{PR}_{1.2 .1}\left\|\mathrm{PR}_{1.2 .2}\right\| \mathrm{PR}_{1.2 .3}\right) \| \\
& \left(\mathrm{PR}_{1.3 .1}\left\|\mathrm{PR}_{1.3 .2}\right\| \mathrm{PR}_{1.3 .3}\left\|\mathrm{PR}_{1.3 .4}\right\| \mathrm{PR}_{1.3 .5} \|\right. \\
& \mathrm{PR}_{1.3 .6}\left\|\mathrm{PR}_{1.3 .7}\right\| \mathrm{PR}_{1.3 .8}\left\|\mathrm{PR}_{1.3 .9}\right\| \\
& \left.\mathrm{PR}_{1.3 .10}\left\|\mathrm{PR}_{1.3 .11}\right\| \mathrm{PR}_{3.12}\right) \\
\mathrm{PA}_{2}= & \mathrm{PC}_{2.1} \| \mathrm{PC}_{2.2} \\
= & \left(\mathrm{PR}_{2.1 .1}\left\|\mathrm{PR}_{2.1 .2}\right\| \mathrm{PR}_{2.1 .3}\left\|\mathrm{PR}_{2.1 .4}\right\| \mathrm{PR}_{2.1 .5} \|\right. \\
& \mathrm{PR}_{2.1 .6}\left\|\mathrm{PR}_{2.1 .7)}\right\|\left(\mathrm{PR}_{2.2 .1}\left\|\mathrm{PR}_{2.2 .2}\right\| \mathrm{PR}_{2.2 .3} \|\right. \\
& \left.\mathrm{PR}_{2.2 .4}\right) \\
\mathrm{PA}_{3}= & \mathrm{PC}_{3.1} \| \mathrm{PC}_{3.2} \\
= & \left(\mathrm{PR}_{3.1 .1}\left\|\mathrm{PR}_{3.1 .2}\right\| \mathrm{PR}_{3.1 .3}\right) \|\left(\mathrm{PR}_{3.2 .1} \| \mathrm{PR}_{3.2 .2}\right. \\
& \left.\left\|\mathrm{PR}_{3.2 .3}\right\| \mathrm{PR}_{3.2 .4}\left\|\mathrm{PR}_{3.2 .5}\right\| \mathrm{PR}_{3.2 .6}\right) \\
\mathrm{PA}_{4}= & \mathrm{PC}_{4.1} \\
= & \left(\mathrm{PR}_{4.1 .1}\left\|\mathrm{PR}_{4.1 .2}\right\| \mathrm{PR}_{4.1 .3}\left\|\mathrm{PR}_{4.1 .4}\right\| \mathrm{PR}_{4.1 .5} \|\right.
\end{aligned}
$$

\section{The Bootstrap Process Assessment Model}

The BOOTSTRAP process model was systematically introduced in above section. This section explored the BOOTSTRAP process capability model and process capability determination methodology. Both of the above forms the BOOTSTRAP process assessment.

\section{A. The Bootstrap Process Capability Model}

This section describes the BOOTSTRAP process capability model, which includes a practice performance scale, and a process capability scale.

1) Practice Performance Scale

A practice performance rating scale for the QSAs in BOOTSTRAP is defined in four (plus one) levels as described in Table III. In this table, the rating thresholds provide a set of quantitative measurements for rating a QSA's performance with the scale.

The supplementary scale 0 in Table III doesn't apply is designed to increase the tailorability and flexibility of the BOOTSTRAP QSA rating, a sore 0 is usually treated as equivalent to 4 .

\section{2) Process Capability Scale}

As shown in Table IV, process capability in BOOTSTRAP is determined by a five-level process capability scale, which is identified to that of CMM. A refinement of the capability scale in BOOTSTRAP is that quartiles are added to each capability level to enable further precise assessment of the process capability.
In table IV, the different distances (number of QSAs) between two adjacent levels indicate the various difficulties in capability improvement from the current level to the next higher level according to the model.

TABLE III Practice Performance Scale of the QSAs

\begin{tabular}{|l|l|l|}
\hline Scale & Description & $\begin{array}{l}\text { Rating } \\
\text { threshold } \\
(\%)\end{array}$ \\
\hline 4 & Complete/extensive & $>=80$ \\
\hline 3 & Largely satisfied & $66.7-79.9$ \\
\hline 2 & Partially satisfied & $33.3-66.6$ \\
\hline 1 & Absent/Poor & $<=33.2$ \\
\hline 0 & Doesn't apply & - \\
\hline
\end{tabular}

It may be observed from table that for process assessment BOOTSTRAP adopted the same approach to pre-assigned the 234 QSAs into different capability levels. BOOTSTRAP overlaps the process and capability dimensions at the practice (QSA) level, CMM overlaps the two dimensions at the process (KPA) level, this means that BOOTSTRAP pre-allocates and determines the process capability levels by different QSAs while CMM does the same by different KPAs. So in BOOTSTRAP, we may say that a capability level is determined by a certain subset of its practices (QSAs); while that of CMM is determined by a certain subsets of its processes (KPAs).

\section{B. The BOOTSTRAP Process capability determination methodology.}

The BOOTSTRAP capability model is applied to the process model for the assessment of process capability using the formal definition of the BOOTSTRAP process model and process capability model developed in section 3.3 and 4.1

\section{1) Process Performance Rating Method:}

Let $r_{\mathrm{QSA}}[\mathrm{i}, \mathrm{j}]$ be a rating of performance of the $j$ th QSA at the ith process capability level. The $r_{Q S A}[i, j]$ can be read according to the practice performance scale as defined in table 3 , i.e.

$\mathrm{r}_{\mathrm{QSA}}[\mathrm{i}, \mathrm{j}]=4$, if the QSA's performance is at least $80 \%$ satisfied

$=3$, if the QSA's performance is between 66.7 $-79.9 \%$ satisfied

$=2$, if the QSA's performance is between 33.3 $-66.6 \%$ satisfied

$=1$, if the QSA's performance is less than 33.2satisfied $=0$, if the QSA's doesn't apply in this

Assessment 
With Educational Maturity Model

TABLE IV. The BOOTSTRAP Process Capability Model

\begin{tabular}{|c|c|c|c|c|}
\hline $\begin{array}{c}\text { Capability } \\
\text { Level } \\
(C L[i]) \\
\end{array}$ & $\begin{array}{c}\text { Quartiles } \\
\text { Between CLs }\end{array}$ & Description & $\begin{array}{c}\text { Identified QSAs } \\
(N q s a[i])\end{array}$ & $\begin{array}{c}\text { Pass Threshold } \\
\text { (Pqsa[i]) }\end{array}$ \\
\hline CL[0] & & Initial & $\mathrm{Nqsa}[0]=0$ & $\mathrm{Pqsa}[0]=0$ \\
\hline CL[1] & $\begin{array}{l}\text { CL1.1 } \\
\text { CL1.2 } \\
\text { CL1.3 } \\
\text { CL1.4 }\end{array}$ & Repeated & $\mathrm{Nqsa}[1]=106$ & $\bar{P} \mathrm{Pqsa}[1]=89$ \\
\hline CL[2] & $\begin{array}{l}\text { CL2.1 } \\
\text { CL2.2 } \\
\text { CL2.3 } \\
\text { CL2.4 }\end{array}$ & Defined & $\mathrm{Nqsa}[1]=54$ & $\mathrm{Pqsa}[1]=43$ \\
\hline CL[3] & $\begin{array}{l}\text { CL3.1 } \\
\text { CL3.2 } \\
\text { CL3.3 } \\
\text { CL3.4 }\end{array}$ & Refined & $\mathrm{Nqsa}[1]=46$ & Pqsa[1] $=37$ \\
\hline$\overline{\mathrm{CL}[4]}$ & $\begin{array}{l} \\
\text { CL4.1 } \\
\text { CL4.2 } \\
\text { CL4. } 3 \\
\text { CL4.4 }\end{array}$ & $\begin{array}{c}\text { Quantifiable } \\
\text { Matured } \\
\text { Process }\end{array}$ & $\mathrm{Nqsa}[1]=28$ & Pqsa[1] $=22$ \\
\hline
\end{tabular}

\section{2) Process Capability Rating Method}

The number of satisfied QSAs at a level i, $\mathrm{SAT}_{\mathrm{QSA}}[\mathrm{i}]$, is assessed according to the following expression.

$$
\begin{aligned}
& \operatorname{SAT}_{\mathrm{QSA}}[\mathrm{i}]=\#\{\mathrm{QSA}[\mathrm{i}, \mathrm{j}] \quad \text { Passed }\} \\
& =\#\left\{\mathrm{QSA}[\mathrm{i}, \mathrm{j}] \mid \mathrm{r}_{\mathrm{QSA}}[\mathrm{i}, \mathrm{j}]>=3 \mathrm{~V} \mathrm{r}_{\mathrm{QSA}}[\mathrm{i}, \mathrm{j}]=0\right\} \\
& \mathrm{N}_{\mathrm{QSAi}}=\sum\left\{1 \mid \mathrm{r}_{\mathrm{QSA}}[\mathrm{i}, \mathrm{j}]>=3 \mathrm{Vr}_{\mathrm{QSA}}[\mathrm{i}, \mathrm{j}]=0\right\} \\
& \mathrm{j}=1
\end{aligned}
$$

Where $\mathrm{N}_{\text {QSAi }}$ is the number of defined QSAs at level i. Expression 2 indicates that the number of the satisfied QSAs at a capability level can be obtained simply by counting the QSAs that satisfy or do not apply in the assessment.

A pass threshold $\mathrm{P}_{\mathrm{QSA}}[\mathrm{i}]$, for a capability level, $\mathrm{i}$ in BOOTSTRAP is defined as:

$\mathrm{P}_{\mathrm{QSA}}[\mathrm{i}],=\mathrm{N}_{\mathrm{QSA}}[\mathrm{i}] * 80 \%$

This means that $80 \%$ of the QSAs defined at a level should be satisfied for fulfilling the requirements of the process capability at this level i.e.

$$
\begin{aligned}
\operatorname{SAT}_{\mathrm{QSA}}[\mathrm{i}] & \geq \mathrm{P}_{\mathrm{QSA}}[\mathrm{i}] \\
& \geq \mathrm{N}_{\mathrm{QSA}}[\mathrm{i}] * 80 \%
\end{aligned}
$$

The pass thresholds at each capability level have been defined in Table 4.

BOOTSTRAP Capability levels and their related QSAs are predefined and fixed according to its methodology, as is the case for CMM. However, BOOTSTRAP allows an organization's practices at higher levels to be taken into account in the final capability determination. This feature is explained in the next section.

\section{3) Product Capability Determination Method}

BOOTSTRAP adopts a dynamic capability scale for process assessment. BOOTSTRAP assesses a system capability by taking account of the practices (QSAs) at all levels. The higher level practices within organizations which, at the levels(s) higher than the maximum fulfilled capability level, are treated as merits in capability determination.

The total score for the education quality system - the number of QSAs satisfied at all levels, $\mathrm{N}_{\mathrm{QSA}}$ - is a sum of the QSAs satisfied at each level i.e.;

$$
\mathrm{N}_{\text {QSA }}[\mathrm{i}]=\sum \quad \underset{j=1}{\mathrm{NATAi}_{\text {QSA }} \text { [i] }}
$$

Thus, the process capability level of a product, PCL, is calculated by the items in BOOTSTRAP, a base score and an additional technical merit score gained (4y practices at higher levels as described below. 


$$
\begin{aligned}
& \mathrm{PCL}=\text { Base }+ \text { Additional } \\
& =\max \left\{\mathrm{i} \mid \mathrm{SAT}^{1}{ }_{\mathrm{QSA}}[\mathrm{i}] \geq \mathrm{P}^{1}{ }_{\mathrm{QSA}}[\mathrm{i}]\right\}+ \\
& \left(\mathrm{SAT}_{\text {QSA }}^{1}[5]-\operatorname{SAT}_{\text {QSA }}^{1}[\mathrm{i}]\right) / \sum_{\mathrm{j}=\mathrm{i}+1}^{5} \mathrm{~N}_{\mathrm{QSA}}[\mathrm{j}]
\end{aligned}
$$

Where $\mathrm{SAT}^{1}{ }_{\mathrm{QSA}}[\mathrm{i}]$ and $\mathrm{P}_{\mathrm{QSA}}^{1}[\mathrm{i}]$ represent the ith accumulated score and threshold up to level i, respectively. The latter can be derived based on the individual pass thresholds defined in Table IV as $\left\{\mathrm{P}_{\mathrm{QSA}}^{1}[0], \mathrm{P}_{\mathrm{QSA}}^{1}[1], \mathrm{P}_{\mathrm{QSA}}^{1}[2], \mathrm{P}_{\mathrm{QSA}}^{1}[3], \mathrm{P}_{\mathrm{QSA}}^{1}[4]\right\}=0$, 89, 132, 169, 191.

When a PCL obtained by Expression 6 is neither an integer nor a quartile, a quarterly rounded capability level, PCL $\tau$, needs to be derived according to the following expression:

$\operatorname{PCL} \tau=[\mathrm{PCL}]_{1 / 4}$

Where $[\mathrm{x}]_{1 / 4}^{1 / 4}$ means round $\mathrm{x}$ to the nearest lower quarter. For example, $[1.80]_{1 / 4}=1.75,[3.23]_{1 / 4}=3.0$, and $[4.5]_{1 / 4}=4.5$.

Thus, the product capability level in BOOTSTRAP can be obtained by substituting Expression 6 into 7

$$
\begin{aligned}
& \mathrm{PCL}_{\text {prod }}=\operatorname{PCL} \tau \\
& \quad=[\mathrm{PCL}]^{1 / 4} \\
& \quad=\max \left\{\mathrm{i} \mid \mathrm{SAT}_{\mathrm{QSA}}^{1}[\mathrm{i}] \geq \mathrm{P}_{\mathrm{QSA}}^{1}[\mathrm{i}]\right\}+ \\
& \quad\left(\mathrm{SAT}_{\mathrm{QSA}}^{1}[5]-\mathrm{SAT}_{\mathrm{QSA}}^{1}[\mathrm{i}]\right) / \sum_{\mathrm{j}=\mathrm{i}+1}^{5} \mathrm{~N}_{\mathrm{QSA}}[\mathrm{j}]_{1 / 4}^{1 / 4}
\end{aligned}
$$

\section{V. . SAMPLE BOOTSTRAP ASSESSMENT}

The capability rating framework and the capability determination algorithm of BOOTSTRAP have been formally described in Sections 3 and 4. This section demonstrates how to apply the BOOTSTRAP expressions and algorithm to quantitatively determine an education system capability level in BOOTSTRAP.

\section{A) QSA performance rating in BOOTSTRAP}

First, a set of detailed ratings of all 234 QSAs is identified. On applying Expression 2 allows the number of QSAs at a level i, $\mathrm{SAT}_{\mathrm{QSA}}[\mathrm{i}]$ to be derived by

$$
\begin{aligned}
& \mathrm{SAT}_{\mathrm{QSA}}[\mathrm{i}]=\#\{\mathrm{QSA}[\mathrm{i}, \mathrm{j}] \mid \text { Passed }\} \\
& =\#\left\{Q S A[i, j] \quad \mid r_{Q S A}[i, j]>=3 \quad V \quad r_{Q S A}[i, j]=0\right\} \\
& \mathrm{N}_{\mathrm{QSAi}} \\
& =\sum_{j=1}\left\{1 \mid r_{Q S A}[i, j]>=3 \quad V \quad r_{Q S A}[i, j]=0\right\}
\end{aligned}
$$

For example, there are $28 \mathrm{QSAs}$ at level $4, \mathrm{CL}_{4}$, in BOOTSTRAP which are identified by subscript "4". If only 20 QSAs $\left\{\mathrm{QSA}_{4.1}=3, \mathrm{QSA}_{4.3}=4, \mathrm{QSA}_{4.7}=3\right.$, $\mathrm{QSA}_{4.8}=4, \mathrm{QSA}_{4.9}=4, \mathrm{QSA}_{4.10}=0, \mathrm{QSA}_{4.11}=3$, $\mathrm{QSA}_{4.12}=0, \mathrm{QSA}_{4.13}=4, \mathrm{QSA}_{4.14}=4, \mathrm{QSA}_{4.15},=0$, $\mathrm{QSA}_{4.16}=4, \mathrm{QSA}_{4.17}=3, \mathrm{QSA}_{4.19}=4, \mathrm{QSA}_{4.20}=0$,

\begin{tabular}{|c|c|c|c|c|}
\hline $\begin{array}{l}\text { Capability } \\
\text { level } \\
\left(\mathrm{CL}_{[i]}\right)\end{array}$ & Description & $\begin{array}{l}\text { Identified } \\
\text { QSAs } \\
\left(\mathrm{N}_{\mathrm{QSA}}[\mathrm{i}]\right)\end{array}$ & $\begin{array}{l}\text { Pass } \\
\text { threshold } \\
\left(\mathrm{P}_{\mathrm{QSA}}[\mathrm{i}]\right. \\
\mathrm{P}_{\mathrm{QSA}}^{1}[\mathrm{i}]\end{array}$ & $\begin{array}{c}\text { Assessment } \\
\text { result } \\
\left(\mathrm{SAT}_{\mathrm{QSA}}[\mathrm{i}] \mid\right. \\
\mathrm{SAT}^{1}{ }_{\mathrm{QSA}}[\mathrm{i}]\end{array}$ \\
\hline $\mathrm{CL}_{[0]}$ & Initial & 0 & $0 \mid 0$ & \begin{tabular}{l|l}
0 & 0
\end{tabular} \\
\hline $\mathrm{CL}_{[1]}$ & Repeated & 106 & $\begin{array}{l}84.8 \\
84.8\end{array}$ & \begin{tabular}{l|l|l}
100 & 100
\end{tabular} \\
\hline $\mathrm{CL}_{[2]}$ & Defined & 54 & $\begin{array}{l}43.2 \\
128\end{array}$ & $50 \mid 150$ \\
\hline $\mathrm{CL}_{[3]}$ & Refined & 46 & $\begin{array}{l}36.8 \mid \\
164.8\end{array}$ & \begin{tabular}{l|l}
10 & 160
\end{tabular} \\
\hline $\mathrm{CL}_{[4]}$ & $\begin{array}{l}\text { Quantifiab } \\
\text { le matured } \\
\text { process }\end{array}$ & 28 & $\begin{array}{l}22.4 \mid \\
187.2\end{array}$ & \begin{tabular}{l|l}
20 & 180
\end{tabular} \\
\hline
\end{tabular}
$\mathrm{QSA}_{4.22}=4, \mathrm{QSA}_{4.23}=4, \mathrm{QSA}_{4.24}=3, \quad \mathrm{QSA}_{4.26}=4$, $\left.\mathrm{QSA}_{4.27}=4\right\}$ are satisfied, then according to Expression 1 , the numbers of satisfied QSAs for $\mathrm{CL}_{4}$ are
$\mathrm{SAT}_{\mathrm{QSA}}[4]=20$

A sample summary of the ratings of the 234 QSAs at 5 capability levels in BOOTSTRAP is listed in Table V. In the last two columns, $\mathrm{P}^{1}{ }_{\mathrm{QSA}}[\mathrm{i}]$ and $\mathrm{SAT}_{\mathrm{QSA}}^{1}[\mathrm{i}]$ represen(6) the ith accumulated threshold and the ith accumulated score at level i, respectively.

TABLE V. SUMMARY ASSESSMENT RECORD IN BOOTSTRAP

\section{B) Process capability determination in BOOTSTRAP.}

Using the assessment result listed in Table V, a process capability profile of the Education development organization in BOOTSTRAP can be derived as shown in Figure 4. The data shown in the $\mathrm{CL}_{\mathrm{i}}{ }^{1}$ columns are the accumulated scores up to level i.

Figure $4 \mathrm{a}$ to $4 \mathrm{~d}$ shows the Process capability profile of an education organization in BOOTSTRAP

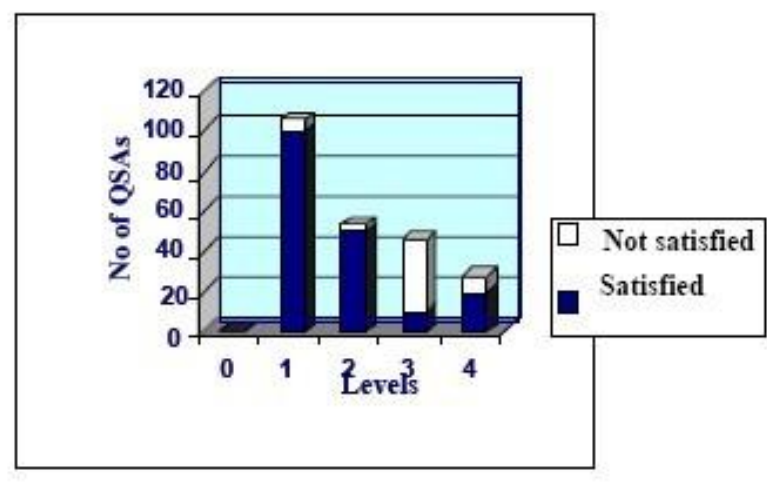

Figure 4a: \# of QSA versus Levels

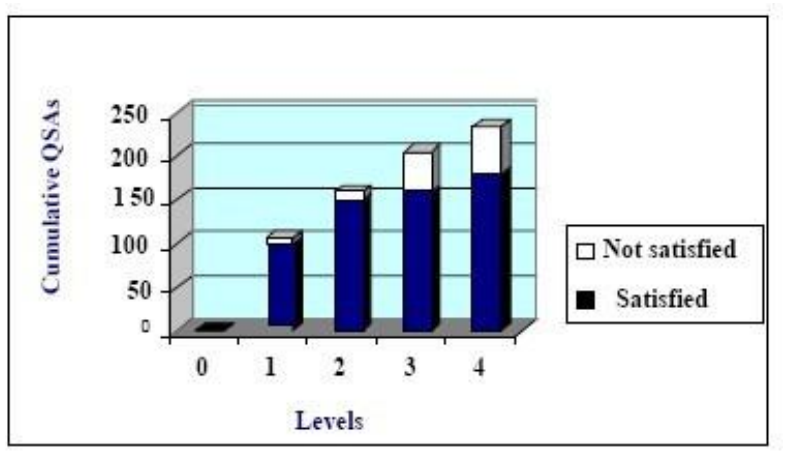

Figure 4b: Cumulative QSAs Versus Levels 


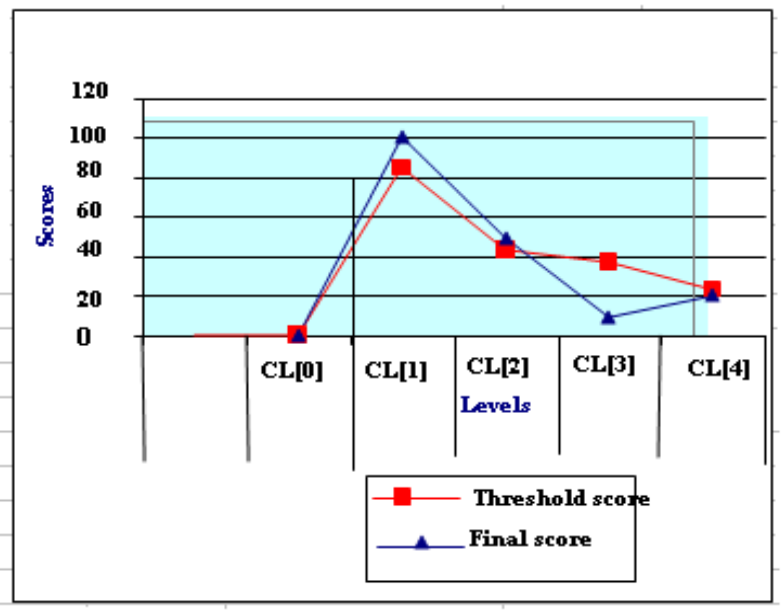

Figure 4c: Threshold score versus Final score

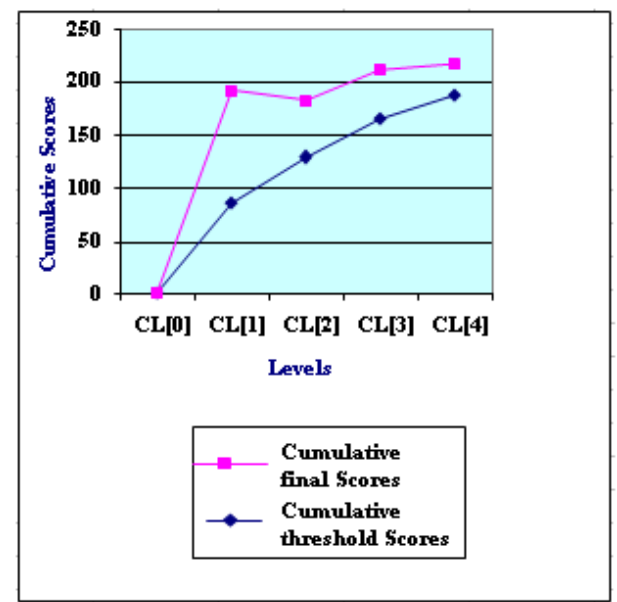

Figure 4d: Cumulative threshold Score versus Levels

\section{C) Education - Capability determination in BOOTSTRAP}

The capability maturity level for a product $p$, PCLprod[p], in BOOTSTRAP has been defined as the maximum integer level, i, plus the quartile(s) a software development organization fulfilled as in Expression 8.

Applying Expression 8 to the ratings of the 234 QSAs at the five levels summarized in Table 5, the capability level of the software development organization can be determined. Considering that:

$$
\begin{aligned}
& \left(\operatorname{SAT}^{1}{ }_{\mathrm{QSA}}[1]=100\right)>\left(\mathrm{P}^{1}{ }_{\mathrm{QSA}}[1]=84.8\right) \\
& \left(\mathrm{SAT}_{\mathrm{QSA}}[2]=150\right)>\left(\mathrm{P}^{1}{ }_{\mathrm{QSA}}[2]=128\right) \\
& \left(\mathrm{SAT}_{\mathrm{QSA}}[3]=160\right)<\left(\mathrm{P}^{1}{ }_{\mathrm{QSA}}[3]=164.8\right) \\
& \left(\mathrm{SAT}_{\mathrm{QSA}}^{1}[4]=180\right)<\left(\mathrm{P}^{1}{ }_{\mathrm{QSA}}^{1}[4]=187.2\right)
\end{aligned}
$$

This indicates that the base score in BOOTSTRAP is 3 . According to Expression 8, the capability level of the education organization in BOOTSTRAP can be calculated as:

$$
\begin{aligned}
& \mathrm{PCL}_{\text {proj }}=\mathrm{PCL} \tau \\
& =\left[\mathrm{PCL}_{1 / 4}^{1 / 4}\right. \\
& =\max \left\{\mathrm{i} \mid \mathrm{SAT}_{\mathrm{QSA}^{1}}[\mathrm{i}] \geq \mathrm{P}_{\mathrm{QSA}}^{1}[\mathrm{i}]\right\}+\left(\mathrm{SAT}_{\mathrm{QSA}}^{1}[4]-\right.
\end{aligned}
$$

$$
\begin{aligned}
\left.\operatorname{SAT}_{\mathrm{QSA}}^{1}[\mathrm{i}]\right) / \sum_{\mathrm{j}=\mathrm{i}+1} \mathrm{~N}_{\mathrm{QSA}}[\mathrm{j}]_{1 / 4} \\
=\max \left\{0,1,2 \mid \mathrm{SAT}_{\mathrm{QSA}}^{1}[\mathrm{i}] \geq \mathrm{P}_{\mathrm{QSA}}^{1}[\mathrm{i}]\right\}+\left(\mathrm{SAT}_{\mathrm{QSA}^{1}}[4]\right. \\
\left.\quad-\mathrm{SAT}_{\mathrm{QSA}}^{1}[\mathrm{i}]\right) / \sum_{\mathrm{j}=\mathrm{i}+1}^{5} \mathrm{~N}_{\mathrm{QSA}}[\mathrm{j}]_{1 / 4} \\
=2+\left(\mathrm{SAT}_{\mathrm{QSA}}^{1}[4]-\mathrm{SAT}_{\mathrm{QSA}}^{1}[2]\right) / \sum_{\mathrm{j}=2+1}^{4} \mathrm{~N}_{\mathrm{QSA}}[\mathrm{j}]_{1 / 4} \\
=2+(180-150) /(46+28) \\
=2+(30 / 74) \\
=2+0.405=2.405_{1 / 4}=2(\text { Level } 2)
\end{aligned}
$$

\section{CONCLUSIONS}

In this paper, we have proposed a Capability Maturity Model for Education System benchmarked with BOOTSTRAP model, which helps in improving the practices of key educational processes and contribute to enhance the overall quality education. For this, we adopted CMM as our base model and proposed a new BOOTSTRAP-CMM-Educational model. The five levels of maturity provides a finer grained measure of the education process maturity in the scale of 0 to 4 , thus facilitating the process of articulation between institutions at the same level and giving an encouraging assessment of institutions, instead of an all-or-nothing accreditation decision. Based on this model, the BOOTSTRAP-assessment methodology is derived to predict the capability level or performance level of an Educational Organization. This BOOTSTRAP-CMMEducational model can be used for continuously evaluating the education process which serves as the mantra for effective accreditation of higher education system. Using this tool, one can predict the quality, maturity and standard of an education system more precisely and concisely compared to ISO standards. Finally, it is concluded that quality assurance is not the destination, but a journey to continuously improve the higher education system.

\section{REFERENCES}

[1] Pankaj Jalote, Professor, Computer Science and Engineering, I. I. T. Kanpur, "Needed - A Capability Maturity Model for Engineering Education", 2005.

[2] Kuvaja P. J, Simila J, Krzanik L, Bicego A, Saukkonen S, \& Koch G, "Software process assessment and improvement - the bootstrap approach", Oxford: Blackwell, 1994.

[3] Koch E, Kim S, "Issues on adopting software product line", In Proceedings of the $11^{\text {th }}$ Asia-Pacific Conference on Software Engineering, pp. 589, 2004

[4] Koh E., Kim S, "Issues on adopting software product line". In Proceedings of the 11th Asia-Pacific 
Conference on Software Engineering, pp. 589, 2004

[5] "THE CAPABILITY MATURITY MODEL", The Guidelines for Improving the Software Process, Carnegie Mellon University, Software Engineering Institute, Reading, Addison Wesley.

[6] M.Maria, P.Larrondo, "Towards an Engineering Education Capability Maturity Model", Proceedings of the American Society for Engineering Education, Annual Conference and Exposition, 2004

[7] Y.C.Cheng and W.M.Tam (2003), "Multi-models of quality in education", Quality Assurance in Education, No.5(1), pp 22-31

\section{AUTHORS}

Prof. R. Manjula received her B.E in Computer Science \& Engineering from University of Vishwesvaraya and Engineering, Bangalore, Karnataka State, India in 1992 and M.E in Software Engineering from Anna University, Tamil Nadu, India in 2001. She is now working as Associate Professor and also as Ph.d affiliated with School of Computing Science and Engineering at Vellore Institute of Technology, Vellore, India. Her area of specialization includes Software Process modeling, Software Metrics, Software Metrics, Software Testing and Metrics, XML-Web Services and Service Oriented Architecture

Prof. J. Vaideeswaran is a Senior Professor in the School of Computing Science and Engineering at Vellore Institute of Technology, Vellore, Tamil Nadu, India. He received his $\mathrm{Ph} \mathrm{D}$ degree in Computer Engineering from Anna University, Chennai, Tamil Nadu, India in 2000. He took his B E , M E in Electronics and Communication Engineering from University of Madras in 1979 and 1981, respectively. He has been in teaching and research, since 1982. His research interests pertains to Coding Theory, Computer Architecture, Robotics, and Software Engineering. 